\title{
A novel approach for producing low cost and highly efficient activated carbon for removing cationic dyes
}

\author{
Fatiha Moughaoui *, Amine Ouaket, Asmae Laaraibi, Souad Hamdouch, Zoubida Anbaoui, \\ Abdelmjid Abourriche and Mohammed Berrada*
}

Biomolecules and Organic Synthesis Laboratory, University Hassan II of Casablanca, Faculty of Sciences Ben M'sick, Department of Chemistry, Av Driss El Harti, Sidi Othman, Casablanca, P.B. 7955, Morocco

\begin{abstract}
Chemical activation was used to prepare a low-cost activated carbon (AC) from an agricultural waste material: sugarcane bagasse. It was used as a green biosorbent for the removal of two cationic dyes from aqueous solutions (Methylene blue (MB) and Malachite Green (MG)). Central composite design (CCD) using response surface methodology (RSM) was applied in this work in order to run a limited number of experiments. The possibility of revealing the interaction of three selected factors: activation temperature, activation time, and chemical impregnation ratios at different levels for the process of preparing the AC were studied. Two-second order quadratic regression models for a yield of AC and capacity of adsorption were developed using JMP Software.
\end{abstract}

The results of the process of optimization were carried out; it showed a good agreement between the predictive response of RSM model and the obtained experimental values with high correlation coefficients $\left(\mathrm{R}^{2}\right)$ which indicates the efficacy of the model. The optimal activated carbon was obtained using $400^{\circ} \mathrm{C}$ activation temperature, 36 min activation time, and 2 impregnation ratio, resulting in $63.12 \%$ of AC yield and $99.86 \%$ for $\mathrm{MB}$ removal and $400^{\circ} \mathrm{C}$ activation temperature, 90 min activation time and 2 impregnation ratio, resulting in $45.69 \%$ of AC yield and $99.75 \%$ for MG removal. Moreover, the comparison between the experimental and the predicted values at optimum conditions was in good agreement with relatively small errors.

This work showed the effectiveness and the performance of preparing activated carbon from sugarcane bagasse, and it recommended as an effective and green biosorbent for the removal of cationic dyes from aqueous solutions.

Keywords: Sugarcane bagasse, activated carbon, adsorption, central composite design, response surface method.

\section{Introduction}

Activated carbon (AC) is a well-known material as a black solid substance resembling granular or powder charcoal. It is a carbonaceous material that has highly developed porosity, high internal surface area and relatively high mechanical strength ${ }^{1-5}$. Activated carbons are widely used as an adsorbent in wastewater and gas treatments.

Activated carbon was used in many applications such as an adsorbent in wastewater, gold purification, metal extraction, gas treatments, medicine, and sewage treatment and as filters in compressed air ${ }^{6}$.

Despite its prolific used in industries, activated carbon remains an expensive material due to its highcost ${ }^{7-9}$. Hence, a considerable effort in recent years has been devoted to investigating the development of activated carbon from low-cost, available, renewable resources, suitable precursors and modifying the *Corresponding author: Fatiha Moughaoui Email address: fatiha.moughaoui@gmail.com DOI: http://dx.doi.org/10.13171/mjc8219040103fm existing methods to produce activated carbon with better properties ${ }^{10}$.

Agricultural wastes have emerged as a better choice and proved to be promising raw materials for the production of activated carbons ${ }^{11}$. Although they can be used as adsorbents without further treatment, activation could enhance their adsorption capacity. Moreover, the benefits of that would also include the removal of waste product and economic gains for products manufactured from abundant sources instead of disposing of it.

Therefore, in our present study, we were focusing on the use of sugarcane bagasse (SB) to produce $\mathrm{AC}$, as a means of replacing the expensive conventional activated carbon for many advantages such as the abundance, low cost and environmentally friendly properties a result, this conversion would add more values to these agricultural commodities, help reduce the cost of waste disposal.

Received March 1, 2019

Accepted March 15, 2019

Published April 1, 2019 
Sugarcane bagasse (SB) is one of the major residues in the sugar production after it is crushed from the sugarcane; every year millions of tons of SB have been generated by the sugarcane industries. This abundant residue has been showed potential as biosorbent in wastewater treatment which encouraging its reuse and recycling ${ }^{12,13}$.

The pollution of environmental water can be attributed to the increasing contamination waste materials resulting from human activities which pose a continuously growing and severe problem and risks to the environment and health ${ }^{14}$. Among the different pollutants of the aquatic ecosystem, dyes are a large and important group of chemicals that appear colored due to the presence of chromophore groups such as nitrous, azo, and carbonyl and also by groups known as auxochromes such as carboxylic acid, sulfonic acid, amino, and hydroxyl groups ${ }^{15}$.

Industries such as textile, leather, paper, and plastics are the important sources of the release of dyes in the municipal wastewater. Discharging these effluents in water bodies affects the life in aquatic environments by reducing light penetration, affects photosynthesis and causing the ruining of soils and poisoning of drinking water. Also, some dyes are either toxic or carcinogenic proprieties due to the presence of chlorides, metals etc., in their structure what can cause a dangerous health hazard to human beings. Besides, dyes cannot be removed by conventional treatment methods such as aerobic and anaerobic microbial degradation, electrochemical degradation, electrocoagulation, liquid-liquid extraction, photochemical, coagulation-flocculation, membrane separation, ion exchange... ${ }^{16}$ due to their generation of hazardous by-products, caused by their complex aromatic compounds.

Several treatment technologies have been already mentioned for decolorizing dyeing wastewater such as adsorption, reverse osmosis, ion exchange, filtration, flotation, membrane, coagulation and flocculation, and ultrafiltration ${ }^{17}$ but the best one of the most promising alternatives efficient technology is the biosorption particularly by activated carbon. It has been extensively studied from an environmental point of view in terms of regeneration capacity and insensitivity to toxic substances. However, this process of biosorption is not only environmental but also effective, economic, feasible and ease of operation ${ }^{18}$.

As far as known to the authors, even though several researchers have been studied the removal of contaminants from wastewater by AC from sugarcane bagasse, No study has been done on optimization of the production of AC from sugarcane bagasse using the response surface methodology (RSM) as a statistical approach that uses quantitative data from appropriate experiments to determine regression model equations and operating conditions. RSM is a collection of mathematical and statistical techniques to select the best performing sample within a limited number of experimental runs ${ }^{19,20}$.

The objective of this work was to produce activated carbon from sugarcane bagasse with chemical activation. Then optimizing preparation parameters using RSM as a design technique by analyzing the effects of independent variables comprising activation temperature, impregnation ratio and activation time on $\mathrm{AC}$ yield and the capacity of removing two cationic dyes: Methylene blue (MB) and Malachite green (MG) from aqueous solution.

\section{Experimental}

\section{Sample collection}

Sugarcane bagasse that used in the present study for the production of activated carbon was obtained from a local sugar factory (Morocco). It was first dried in sunlight then ground in a laboratory mill into small pieces. The fibers were sieved to pass a $150 \mu \mathrm{m}$ size screen. This fraction was applied as well for the preparation of the activated carbons.

Table 1. Some characteristics of the dyes used as adsorbates.

\begin{tabular}{|l|c|c|}
\hline Dye & $\mathrm{MB}$ & \\
\hline Chemical formula & & MG \\
\hline Structure & $\mathrm{C}_{16} \mathrm{H}_{18} \mathrm{~N}_{3} \mathrm{ClS}$ \\
\hline Molecular weight $(\mathrm{g} / \mathrm{mol})$ & 319.85 & \\
\hline Wavelength $(\mathrm{nm})$ & 664 & \\
\hline
\end{tabular}

\section{Adsorbates}

Cationic basic dyes, Methylene Blue (MB) and Malachite Green (MG) were chosen as the adsorbate in this study, and some of their characteristics are shown in Table 1 . The stock solution was prepared by dissolving $1 \mathrm{~g}$ of dye in $1 \mathrm{~L}$ distilled water. All 
working solutions have been prepared from the stock solution by dilution with distilled water to the needed concentration.

\section{Preparation of the activated carbon}

In the impregnation process, powdered raw bagasse was fully immersed in activating agent preadjusted concentration with different impregnation ratio (x), and it was left overnight.

The impregnated bagasse is then carbonized using a muffle furnace which allows a limited supply of air at a set temperature for a fixed period. Produced activated carbon was repeatedly washed with hot distilled water until achieved a neutral $\mathrm{pH}$ of activated carbon. Finally, it was oven dried at 100 ${ }^{\circ} \mathrm{C}$ to constant weight and sieved with a $100 \mu \mathrm{m}$ mesh screen in order to obtain a fine powder which was preserved in an airtight vial and used for the various experiments. The domains of variation of activation temperature, activation time and percentage of the chemical activated agent were defined on the univariate analysis.

\section{Univariate analysis}

This step considered the first step for producing activated carbon; it consisted of doing a univariate study by setting the experimental domain for each selected factor (Table 2). The goal of this study is to analyze each factor separately by varying it on several levels and then attribute experimental design or develop our experimental matrix.

Table 2. Different variables of the univariate study.

\begin{tabular}{|l|c|}
\hline Factor & Levels \\
\hline Choice of chemical activating agent & $\mathrm{KOH}, \mathrm{NaOH}, \mathrm{K}_{2} \mathrm{CO}_{3}, \mathrm{HNO}_{3}, \mathrm{H}_{3} \mathrm{PO}_{4}, \mathrm{H}_{2} \mathrm{SO}_{4}$ \\
\hline Impregnation ratio (w/w) & $0.5-3$ \\
\hline Time (min) & $30-240$ \\
\hline Temperature $\left({ }^{\circ} \mathrm{C}\right)$ & $250-600$ \\
\hline Percentage of the chemical activating agent (\%) & $50-100$ \\
\hline
\end{tabular}

\section{Optimization of activated carbon production by the experimental design technique}

After the detection of the most influential experimental factors on the adsorption capacity of activated carbons, a standard response surface methodology (RSM) approach by central composite design (CCD) was employed in this work to investigate the variables for preparation of adsorbent material from sugarcane bagasse.

Central composite design is a very efficient approach; it was used to develop a correlation between the activated carbon preparation variables to the dye removal and $\mathrm{AC}$ yield, hence fitting experimental data in the second order model. In this method, each factor is given in the form of coded variables $\left(\mathrm{X}_{\mathrm{i}}\right)$ with no units, to permit comparison of factors of different natures, variables are coded at three equally spaced levels $-1,0,+1$ for low, intermediate and high values respectively.

For three variables, the number of experimental runs from the central composite design (CCD) consists of eight factorial points, six axial points and two replications at the centre points, which gives 16 experiments in total. The experimental sequence was randomized for minimizing the effects of the uncontrolled factors. The responses are given in the form of coded variables (Yi). Each response was used to evolve an empirical model which correlated the three preparation process variables to the response by a second-order polynomial regression model equation expressed by the equation (1) bellow ${ }^{21}$ :

$$
Y=a_{0}+\sum_{i=1}^{n} a_{i} x_{i}+\sum_{i=1}^{n} a_{i i} x_{i}^{2}+\sum_{i=1}^{n} \sum_{j=i+1}^{n} a_{i j} x_{i} x_{j}
$$

Where $\mathrm{Y}$ is the predicted response, $\mathrm{a}_{0}, \mathrm{a}_{\mathrm{i}}, \mathrm{a}_{\mathrm{ii}}, \mathrm{a}_{\mathrm{i}}$ are the regression coefficient $\left(\mathrm{a}_{0}\right.$ is the constant term, $a_{i}$ is a linear effect term, $a_{i i}$ is a quadratic effect term, and $\mathrm{a}_{\mathrm{ij}}$ is an interactive effect term).

The software design expert JMP 13 was used to analyze the regression of experimental data, to fit the equations developed and to plot the response surface. The significative statistical parameters of the experimental models, coefficients, and residue were analyzed using analysis of variance (ANOVA).

\section{Determination of responses}

Adsorption experiments of dyes on activated carbon prepared from sugarcane bagasse were carried. $50 \mathrm{mg}$ of the AC sample was added to 50 $\mathrm{mL}$ of dye solution of known concentration $20 \mathrm{mg} / \mathrm{L}$, and the mixture was taken in a $150 \mathrm{~mL}$ Erlenmeyer flasks. Then it was agitated out at laboratory temperature at a constant speed of $120 \mathrm{rpm}$ for $2 \mathrm{~h}$ continuously to ensure better contact between the dye and the active sites of the product.

The concentration of dyes in each sample was determined using UV-Visible spectrophotometer (UV-3100PC) by monitoring the absorbance at the wavelength of each dye.

\section{Adsorbent material yield}

The prepared activated carbon yield which is regarded as an indicator of the process efficiency for 
activated carbon preparation can be stated as the following equation (2):

$Y_{1}=$ Yield $(\%)=\frac{W_{2}}{W_{1}} * 100$

Where $W_{2}$ and $W_{1}$ are weights of the final activated carbon $(\mathrm{g})$ obtained and the precursor $(\mathrm{g})$ respectively, both based on dry weight.

\section{Capacity of adsorption}

By knowing the initial and the equilibrium concentrations of dye, the efficiency of adsorption or the percentage removal of dyes at equilibrium by activated carbon product was calculated by using the following equation (3):
$Y_{2}=R(\%)=\frac{C_{0}-C_{e}}{C_{0}} * 100$

Where $\mathrm{C}_{0}$ and $\mathrm{C}_{\mathrm{e}}$ are the initial and equilibrium dye concentrations $(\mathrm{mg} / \mathrm{L})$ respectively.

\section{Results and Discussion}

The analysis of process variables by the univariate study allowed selecting the experimental domains for each of the three selected factors to be optimized. The independent variables were activation temperature $\left(\mathrm{X}_{1}\right)$, activation time $\left(\mathrm{X}_{2}\right)$ and impregnation ratio $\left(\mathrm{X}_{3}\right)$. Table 3 given the results of the levels and the range of independent variables and their

levels.

Table 3. Experimental domains of the different factors and their levels intervener in the elaboration of adsorbent materials.

\begin{tabular}{|l|c|c|c|}
\hline Factors & Lower Level (-1) & Central points $(0)$ & Higher level $(+1)$ \\
\hline $\begin{array}{l}\text { Activation temperature } \\
\left(\mathbf{X}_{1}\right)\end{array}$ & $400{ }^{\circ} \mathrm{C}$ & $500{ }^{\circ} \mathrm{C}$ & $600{ }^{\circ} \mathrm{C}$ \\
\hline Activation time $\left(\mathbf{X}_{\mathbf{2}}\right)$ & $30 \mathrm{~min}$ & $60 \mathrm{~min}$ & $90 \mathrm{~min}$ \\
\hline Impregnation ratio $\left(\mathbf{X}_{3}\right)$ & 1 & 1,5 & 2 \\
\hline
\end{tabular}

Table 4. Experimental design in coded and reels variables for central composite design.

\begin{tabular}{|c|c|c|c|c|c|c|c|c|c|}
\hline \multirow[t]{2}{*}{ Run no. } & \multicolumn{3}{|c|}{ Coded level } & \multicolumn{3}{|c|}{ Actual parameters } & \multirow{2}{*}{$\begin{array}{c}\text { Activated Carbon Yield } \\
\text { Y (\%) }\end{array}$} & \multirow{2}{*}{$\begin{array}{c}\text { MB Removal } \\
\text { R }(\%)\end{array}$} & \multirow{2}{*}{$\begin{array}{c}\text { MG Removal } \\
\text { R }(\%)\end{array}$} \\
\hline & $\mathbf{X}_{1}$ & $\mathbf{X}_{2}$ & $\mathbf{X}_{\mathbf{3}}$ & $\mathbf{T}\left({ }^{\circ} \mathbf{C}\right)$ & $\mathbf{t}(\min )$ & $\mathbf{X}$ & & & \\
\hline 1 & 0 & 0 & 0 & 500 & 60 & 1,5 & 38,6 & 99,31 & 98,26 \\
\hline 2 & 1 & 1 & -1 & 600 & 90 & 1 & 6,6 & 99,48 & 98,57 \\
\hline 3 & 0 & 0 & -1 & 500 & 60 & 1 & 31,65 & 99,41 & 98,62 \\
\hline 4 & 0 & 0 & 1 & 500 & 60 & 2 & 40 & 99,61 & 98,57 \\
\hline 5 & 0 & 1 & 0 & 500 & 90 & 1,5 & 24,6 & 98,99 & 98,78 \\
\hline 6 & 1 & 1 & 1 & 600 & 90 & 2 & 15,05 & 99,69 & 99,13 \\
\hline 7 & -1 & 1 & -1 & 400 & 90 & 1 & 36,35 & 98,96 & 99,59 \\
\hline 8 & -1 & 0 & 0 & 400 & 60 & 1,5 & 48,1 & 99,55 & 99,27 \\
\hline 9 & 0 & 0 & 0 & 500 & 60 & 1,5 & 33,3 & 99,41 & 98,47 \\
\hline 10 & 0 & -1 & 0 & 500 & 30 & 1,5 & 39,35 & 99,38 & 97,9 \\
\hline 11 & 1 & -1 & 1 & 600 & 30 & 2 & 30 & 99,69 & 99,03 \\
\hline 12 & -1 & -1 & 1 & 400 & 30 & 2 & 66,75 & 99,79 & 98,52 \\
\hline 13 & -1 & -1 & -1 & 400 & 30 & 1 & 55,1 & 99,83 & 98,67 \\
\hline 14 & 1 & -1 & -1 & 600 & 30 & 1 & 30,2 & 99,72 & 98,57 \\
\hline 15 & -1 & 1 & 1 & 400 & 90 & 2 & 43,85 & 99,5 & 99,74 \\
\hline 16 & 1 & 0 & 0 & 600 & 60 & 1,5 & 20,65 & 99,76 & 98,67 \\
\hline
\end{tabular}

\section{Development of regression model equations}

The central composite design has been used in order to develop correlation existing between the response functions studied: adsorption capacity and activated carbon yield, and the activated carbon preparation variables as well as to find out those conditions that optimized the process by only a minimum number of experiments.
The complete design matrix showing the obtained experimental results is given in Table 4. To determine the experimental error and the reproducibility of the data runs 1-9 at the center point were used.

Regression analysis was performed to fit the responses function and the final empirical models in terms of coded factors for responses of AC yield 
$\left(\mathrm{Y}_{1}\right)$ and cationic dyes adsorption capacity $\left(\mathrm{Y}_{2}\right.$ for $\mathrm{MB})\left(\mathrm{Y}_{3}\right.$ for $\left.\mathrm{MG}\right)$. The quadratic models were selected as proposed by the software and expressed by equations as follows:

$$
\begin{gathered}
Y_{1}=34,512-14,765 X_{1}-9,495 X_{2}+3,575 X_{3}+0,387 X_{1} X_{2}-1,3625 X_{1} X_{3}+0,562 X_{2} X_{3}+0,581 X_{1}^{2} \\
-1,818 X_{2}^{2}+2,031 X_{3}^{2} \\
Y_{2}=99,373+0,071 X_{1}-0,179 X_{2}+0,088 X_{3}+0,115 X_{1} X_{2}-0,04 X_{1} X_{3}+0,1025 X_{2} X_{3}+0,275 X_{1}^{2} \\
-0,194 X_{2}^{2}+0,130 X_{3}^{2} \\
Y_{3}=98,419-0,182 X_{1}+0,312 X_{2}+0,097 X_{3}-0,255 X_{1} X_{2}+0,127 X_{1} X_{3}+0,05 X_{2} X_{3}+0,523 X_{1}^{2} \\
-0,106 X_{2}^{2}+0,148 X_{3}^{2}
\end{gathered}
$$

In this experiment, the $\mathrm{R}^{2}$ values for $\mathrm{Y}_{1}$ and $\mathrm{Y}_{2}$ and $\mathrm{Y}_{3}$ were 0,$98 ; 0.98$ and 0,96 (Figure 1), respectively. They were relatively high and closer to unity, which can indicate that there is an agreement between the model prediction and the experimental data, as a result of that, they judged the fit quality and the suitability of the model's equations. This can indicate that $98 \%, 98 \%$ and $96 \%$ of the total variation in the yield and adsorption capacity of MB and MG dyes, respectively, was attributed to the experimental variables studied.

(a)

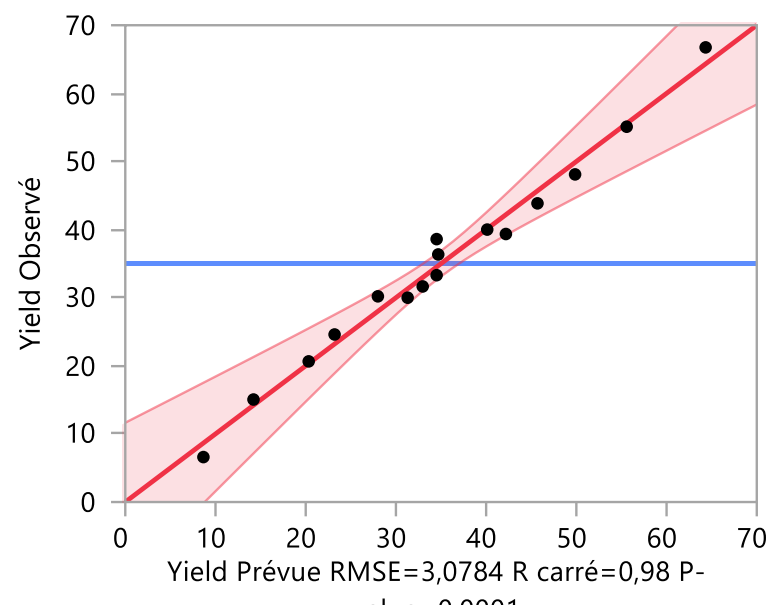

(b)

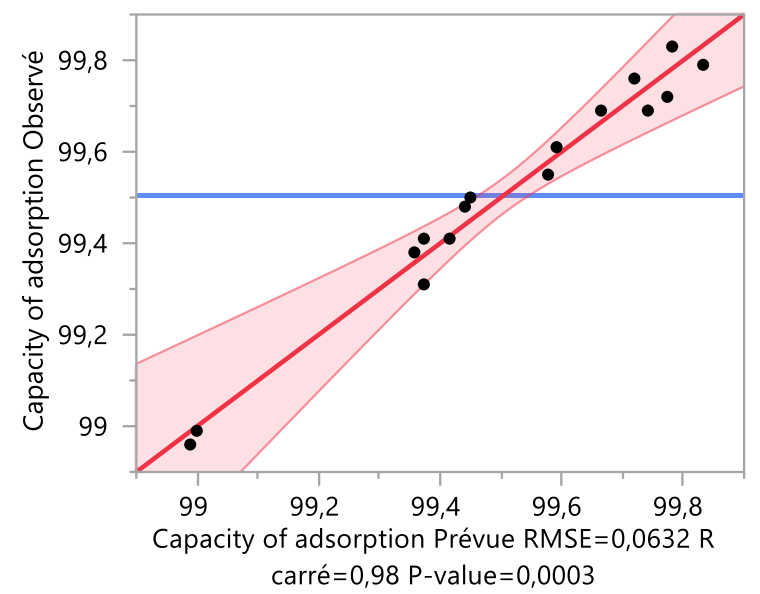

(c)

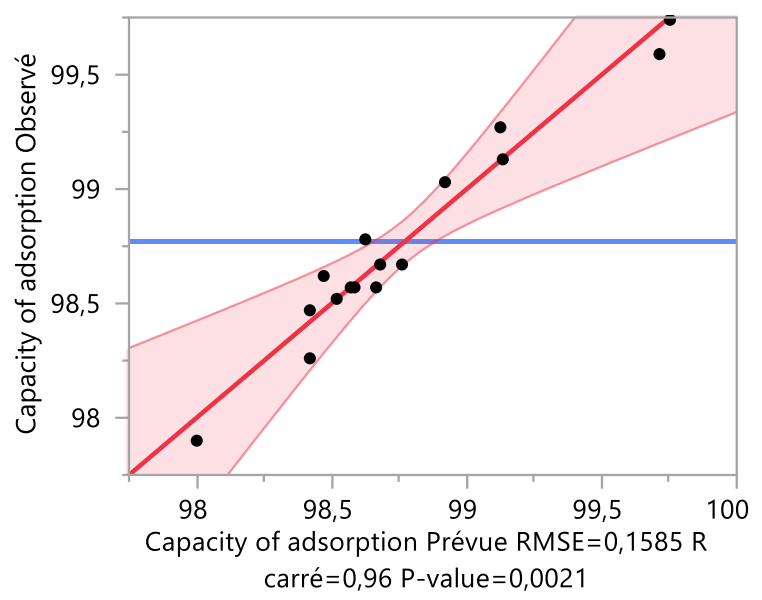

Figure 1. Comparison plot between the experimental and model-predicted (a) Yield (b) MB (c) MG

\section{Statistical analysis}

Analysis of variance (ANOVA)

ANOVA of the quadratic polynomial regression model is mainly realized to further justify the adequacy of the model, and the results are listed in
Tables 5, 6 and 7. The model and factor significance can be stated by corresponding Fisher's statistical test (F-test) and probability-values (p-value) at 95\% confidence of ANOVA study. For any parameter, if the value of Prob>F less than 0.05, the model terms indicate that they were significant evidence that the 
coefficient is not zero whereas if the p-values lower than 0.05 indicated that the model terms are insignificant these terms could be removed from the model equation in order to increase the $\mathrm{R}^{2}$ value, so as to improve the fitting ${ }^{22,23}$.

Table 5. Analysis of Variance (ANOVA) for response surface quadratic model for AC yield.

\begin{tabular}{|l|c|c|c|c|c|}
\hline Source & $\begin{array}{c}\text { Degrees of } \\
\text { Freedom }\end{array}$ & Sum of squares & $\begin{array}{c}\text { Average } \\
\text { square }\end{array}$ & F value & Prob. $>$ F \\
\hline Model & 9 & 3244,6459 & 360,516 & 38,0424 & 0,0001 \\
\hline$X_{1}(400,600)$ & 1 & 2180,0522 & 2180,0522 & 230,0433 & $<, 0001$ \\
\hline$X_{2}(30,90)$ & 1 & 901,5503 & 901,5503 & 95,1333 & $<, 0001$ \\
\hline$X_{3}(1,2)$ & 1 & 127,8063 & 127,8063 & 13,4864 & 0,0104 \\
\hline$X_{1} * X_{2}$ & 1 & 1,2013 & 1,2013 & 0,1268 & 0,7340 \\
\hline$X_{1} * X_{3}$ & 1 & 14,8513 & 14,8513 & 1,5671 & 0,2572 \\
\hline$X_{2} * X_{3}$ & 1 & 2,5313 & 2,5313 & 0,2671 & 0,6238 \\
\hline$X_{1} * X_{1}$ & 1 & 0,8927 & 0,8927 & 0,0942 & 0,7693 \\
\hline$X_{2} * X_{2}$ & 1 & 8,7145 & 8,7145 & 0,9196 & 0,3746 \\
\hline$X_{3} * X_{3}$ & 1 & 10,8845 & 10,8845 & 1,1486 & 0,3251 \\
\hline
\end{tabular}

Table 6. Analysis of variance (ANOVA) for response surface quadratic model for BM removal.

\begin{tabular}{|l|c|c|c|c|c|}
\hline Source & $\begin{array}{c}\text { Degrees of } \\
\text { freedom }\end{array}$ & $\begin{array}{c}\text { Sum of } \\
\text { squares }\end{array}$ & $\begin{array}{c}\text { Average } \\
\text { square }\end{array}$ & F value & Prob. > F \\
\hline Model & 9 & 0,9902 & 0,1100 & 27,5497 & 0,0003 \\
\hline $\mathrm{X}_{1}(400,600)$ & 1 & 0,0504 & 0,0504 & 12,6223 & 0,0120 \\
\hline $\mathrm{X}_{2}(30,90)$ & 1 & 0,3204 & 0,3204 & 80,2281 & 0,0001 \\
\hline $\mathrm{X}_{3}(1,2)$ & 1 & 0,0774 & 0,0774 & 19,3904 & 0,0046 \\
\hline $\mathrm{X}_{1} * \mathrm{X}_{2}$ & 1 & 0,1058 & 0,1058 & 26,4915 & 0,0021 \\
\hline $\mathrm{X}_{1} * \mathrm{X}_{3}$ & 1 & 0,0128 & 0,0128 & 3,2050 & 0,1236 \\
\hline $\mathrm{X}_{2} * \mathrm{X}_{3}$ & 1 & 0,0840 & 0,0840 & 21,0455 & 0,0037 \\
\hline $\mathrm{X}_{1} * \mathrm{X}_{1}$ & 1 & 0,1998 & 0,1998 & 50,0472 & 0,0004 \\
\hline $\mathrm{X}_{2} * \mathrm{X}_{2}$ & 1 & 0,0998 & 0,0998 & 25,0125 & 0,0024 \\
\hline $\mathrm{X}_{3} * \mathrm{X}_{3}$ & 1 & 0,0447 & 0,0447 & 11,2154 & 0,0154 \\
\hline
\end{tabular}

Table 7. Analysis of variance for response surface quadratic model for MG removal.

\begin{tabular}{|l|c|c|c|c|c|}
\hline Source & $\begin{array}{c}\text { Degrees of } \\
\text { freedom }\end{array}$ & Sum of squares & $\begin{array}{c}\text { Average } \\
\text { square }\end{array}$ & F value & Prob. > F \\
\hline Model & 9 & 3,2417097 & 0,360190 & 14,3321 & 0,0021 \\
\hline$X_{1}(400,600)$ & 1 & 0,3312 & 0,3312 & 13,1802 & 0,0110 \\
\hline$X_{2}(30,90)$ & 1 & 0,9734 & 0,9734 & 38,7335 & 0,0008 \\
\hline$X_{3}(1,2)$ & 1 & 0,0940 & 0,0940 & 3,7439 & 0,1012 \\
\hline$X_{1} * X_{2}$ & 1 & 0,5202 & 0,5202 & 20,6989 & 0,0039 \\
\hline$X_{1} * X_{3}$ & 1 & 0,1300 & 0,1300 & 5,1747 & 0,0632 \\
\hline$X_{2} * X_{3}$ & 1 & 0,0200 & 0,0200 & 0,7958 & 0,4067 \\
\hline$X_{1} * X_{1}$ & 1 & 0,7218 & 0,7218 & 28,7240 & 0,0017 \\
\hline$X_{2} * X_{2}$ & 1 & 0,0300 & 0,0300 & 1,1948 & 0,3163 \\
\hline$X_{3} * X_{3}$ & 1 & 0,0579 & 0,0579 & 2,3063 & 0,1796 \\
\hline
\end{tabular}

According to data of Tables 5,6 and 7, the ANOVA results were statistically significant for all the responses $\mathrm{AC}$ yield model and cationic dyes removal model because the Prob $>\mathrm{F}$ values and less than $0.05 \mathrm{P}_{\text {yield }}=0,0001, \mathrm{P}_{\mathrm{BM}}=0.0003, \mathrm{P}_{\mathrm{GM}}=0,0021$ respectively. In contrast, values $\mathrm{P}>0.05$ indicated that the model terms were not significant. Then, activation temperature $\left(\mathrm{X}_{1}\right)$ and activation time $\left(\mathrm{X}_{2}\right)$ were significant model terms whereas impregnation ratio $\left(\mathrm{X}_{3}\right)$ term was not significant for MG removal $(\mathrm{P}=0.1012)$ but significant for $\mathrm{AC}$ yield variable and $\mathrm{BM}$ removal variable $(\mathrm{P}<0.05)$. 
Finally, consideration of normal probability and comparison of observed and predicted values obtained from the statistical results, we summarize that the above models were adequate to predict the values of the responses studied within the range of variables studied.

\section{Interaction effects of the preparation parameters on the yield and the adsorption capacity}

Three-dimensional view of response surface plots was applied for illustrating the progression of one response studied according to the progress of various operational parameters or factors. The plots were represented as a function of two factors at a time and holding the other factor at a fixed level.

\section{Adsorbent material yield}

The yield of the prepared activated carbon over different combinations of independent variables was

(a)

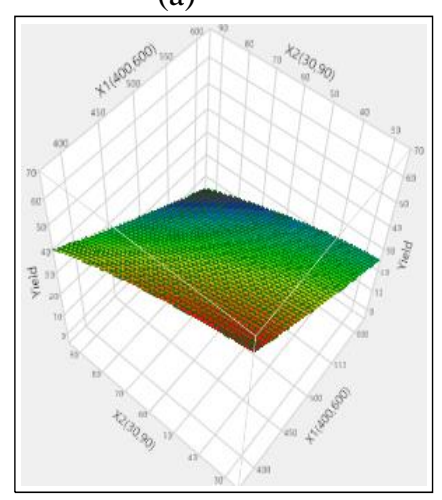

(b)

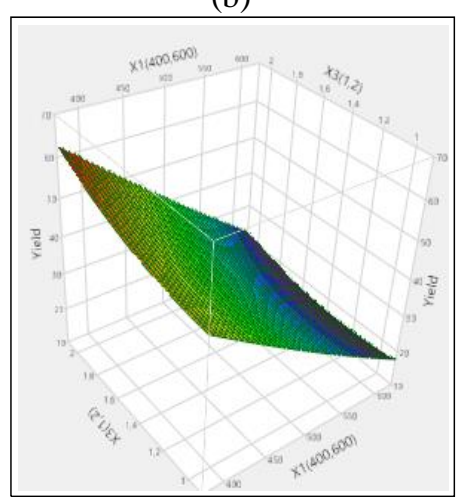

represented through a three-dimensional view of response surface plots (Figure 2). The result of the plot corresponding to this model shows that: AC yield was decreased with increasing activation temperature and activation time but increases with impregnation ratio. From both Figure 2 (a) and (b), it can be seen that the activation temperature was further influential than the other variables. This result was shown a good agreement with the results in Table 5 which draw that the three factors were found to be significantly influencing on the AC yield, with activation temperature imposing the greatest effect on it, with the highest F-value of 230,043 , followed by activation time, however impregnation ratio did not show much effect on the carbon yield which was less significant. While the interaction effects between the variables were all no significant.

Figure 2. 3D response surface of interactive effects on yield of: (a) temperature and time (b) temperature and impregnation ratio (c) time and impregnation ratio 
(a)

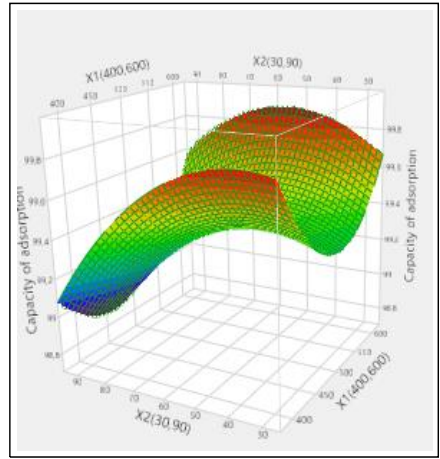

(d)

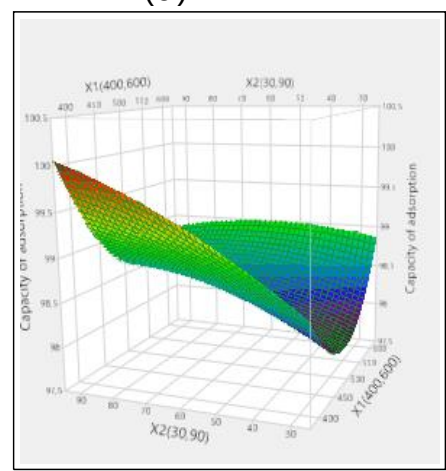

(b)

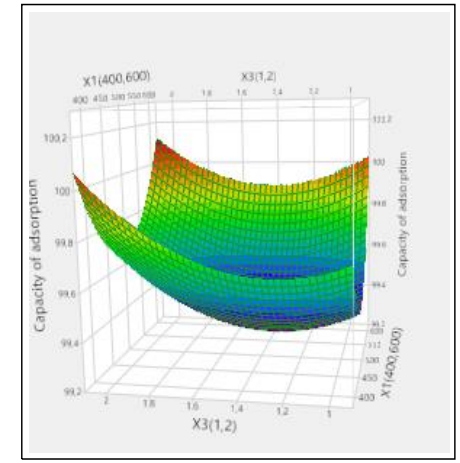

(e)

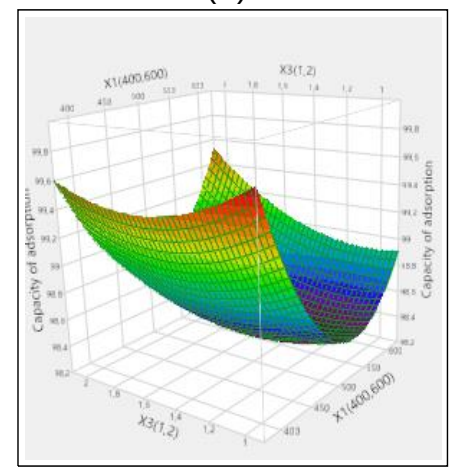

(c)

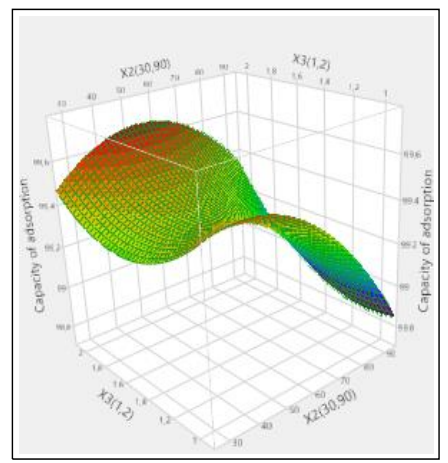

(f)

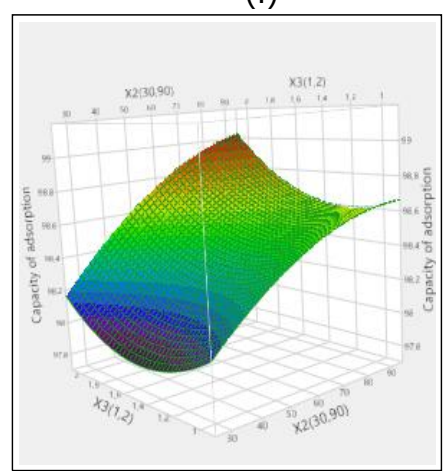

Figure 3. 3D response surface interactive effects of: (a) Temperature and time on MB. (b) Temperature and impregnation ratio on MB. (c) Time and impregnation ratio on MB. (d) Temperature and time on MG (e)

Temperature and impregnation ration on MG. (f) Time and impregnation ratio on MG.

\section{Adsorption capacity}

The plots of the response surface (3D) showed by Figure 3, present the effect of different combinations of independent variables on the response of capacity of adsorption of $\mathrm{MB}$ and GM. According to the plot (3D), an increase of activation temperature reduces adsorption capacity values for both dyes. Further, as can be observed, the continuing increment of activation time promotes a marked increase in adsorption capacity of MG and the contrary on $\mathrm{MB}$.
Referring on the ANOVA results obtained in Tables 6 and 7 and according to the $F$ values, activation time has the most influence on the capacity of adsorption for the dyes studied followed by the quadratic effect of activation temperature afterwards the interaction between activation time and activation temperature. Impregnation ratio, on the other hand, was found to have significant effects on the adsorption of $\mathrm{MB}$ and no significant effects on the adsorption of MG. 


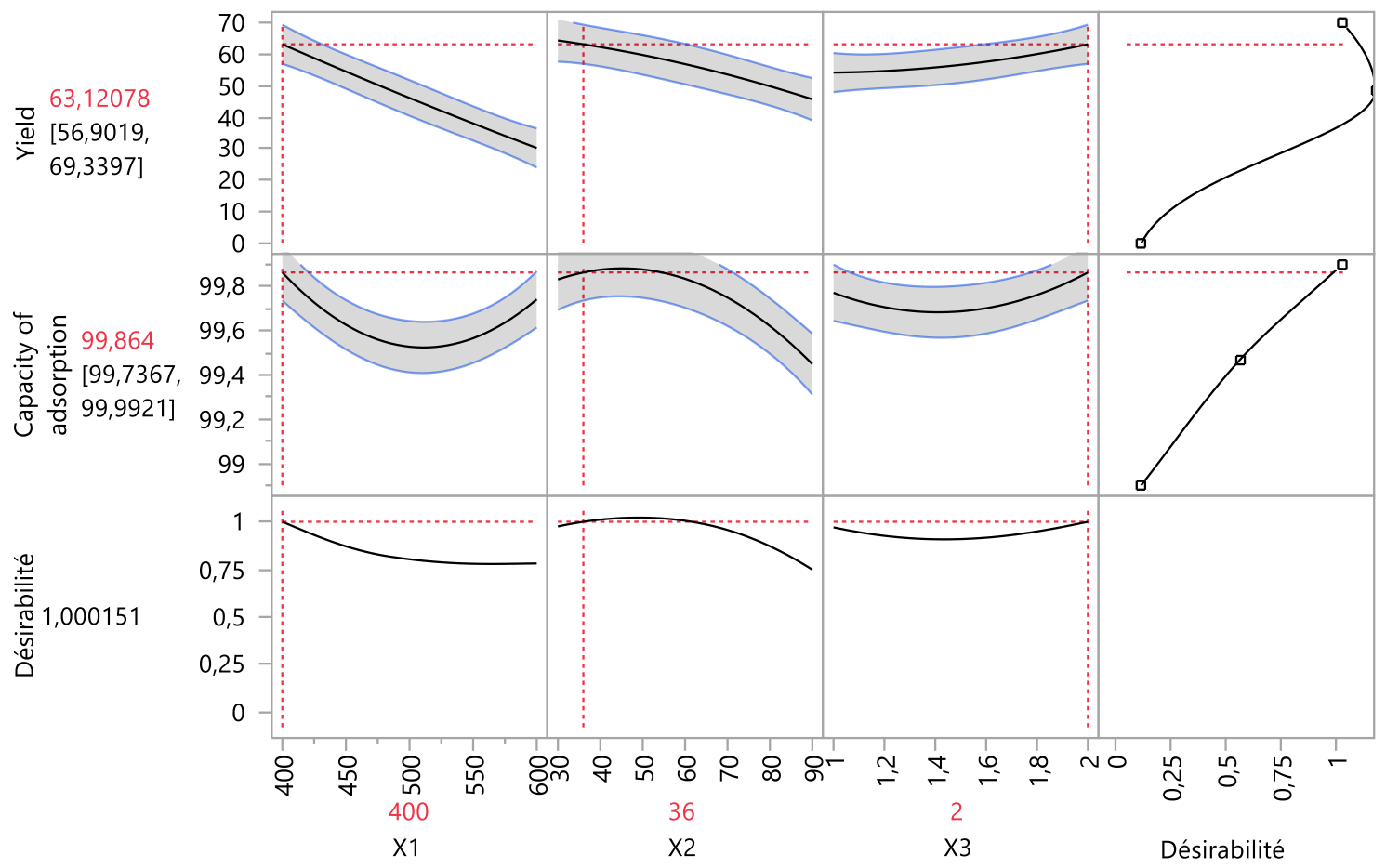

Figure 4. Profiles for predicted that displays the models and settings contributing to achieving the overall maximum desirability for MB

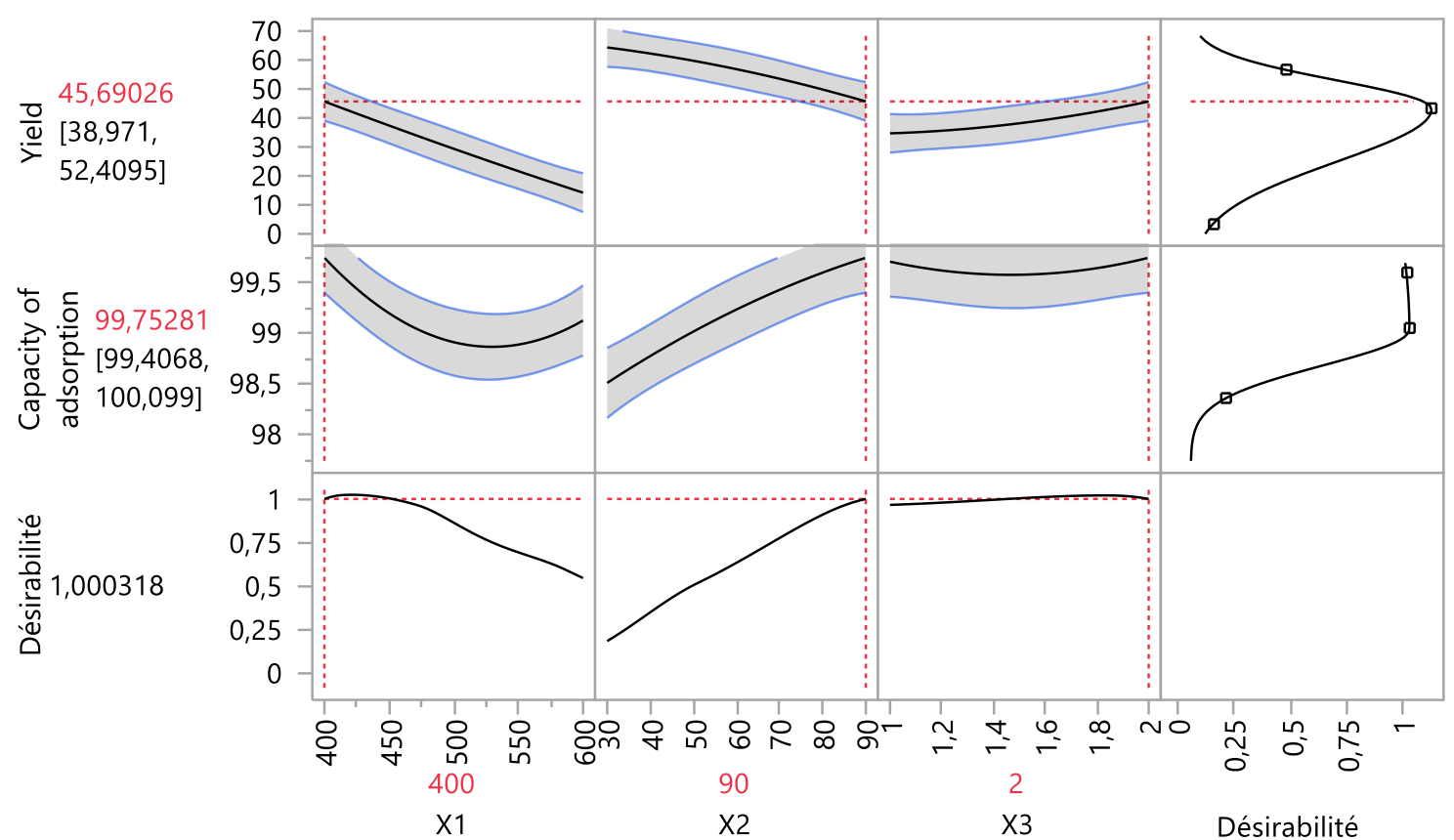

Figure 5. Profiles for predicted that displays the models and settings contributing to achieving the overall maximum desirability for $\mathrm{MG}$

\section{Optimization and validation}

The main objective of the optimization was to find out the optimum conditions of the process which AC product should have a high yield and adsorption capacity for economic feasibility. However, to optimize both responses under the same conditions is difficult because the interest regions of them are different. Hence, to compromise between the two responses, the desirability function was applied using JMP software. The experimental conditions with the highest desirability (corresponding to the maximum satisfaction) were selected to be verified.

The results as shown in Figures 4 and 5, the optimal adsorbent material was obtained using the preparation conditions as $36 \mathrm{~min}$ for activation time, $400^{\circ} \mathrm{C}$ for activation temperature, and impregnation ratio of 2 for the maximum response in $63,12 \%$ of mass yield and $99.86 \%$ of MB adsorption capacity. They also showed $90 \mathrm{~min}$ for activation time, $400^{\circ} \mathrm{C}$ for activation temperature, and impregnation ratio of 
2 for the maximum response in $45,89 \%$ of mass yield of this test are shown in Table 8 . and $99.75 \%$ of MG adsorption capacity. The results

Table 8. The optimized conditions.

\begin{tabular}{|l|c|c|}
\hline & MB & GM \\
\hline Temperature & 400 & 400 \\
\hline Time & 36 & 90 \\
\hline Impregnation ratio & 2 & 2 \\
\hline
\end{tabular}

To verify the validity of this method, a comparison between the experimental and the model predicted results were studied by the preparation of activated carbon samples under the above experimental conditions. From the result shown in
Table 9, it is clear that there is a good agreement existing between the experimental values and those calculated from the models, with mainly small errors less than $5 \%$ for all the responses between the predicted and the actual values.

Table 9. Comparison of predicted and experimental response values for the AC prepared at optimum conditions.

\begin{tabular}{|l|c|c|c|c|}
\hline \multirow{2}{*}{ Adsorbate } & \multicolumn{2}{|c|}{ Yield } & \multicolumn{2}{c|}{ Capacity of adsorption } \\
\cline { 2 - 5 } & Predicted & Experimental & Predicted & Experimental \\
\hline MB & 63,12 & 60,60 & 99,86 & 99,72 \\
\hline MG & 45,69 & 43,60 & 99,75 & 99,44 \\
\hline
\end{tabular}

\section{Conclusion}

The optimization of conditions of the activated carbon preparation such as activation temperature, activation time and impregnation ratio was done. In this study, to achieve better AC yield and cationic dyes removal, we established good conditions using our response surface methodology (RSM) approach. Central composite design of the RSM method was successfully used, and the yield and adsorption capacity of $\mathrm{AC}$ was calculated as a response.

The main conclusions that can be drawn from this study are given below:

-The experimental values obtained were found to agree satisfactorily with the values predicted by model according to the high correlation coefficients $\left(\mathrm{R}^{2}\right)$ and showing the sufficiency of the model in predicting response.

-The optimum points for activation time, activation temperature, and impregnation ratio was found to be $36 \mathrm{~min}, 400{ }^{\circ} \mathrm{C}$, and 2 respectively, resulting in $63.12 \%$ of $\mathrm{AC}$ yield and $99.86 \%$ for MB removal and $90 \mathrm{~min}, 400{ }^{\circ} \mathrm{C}$, and 2 respectively, resulting in $45.69 \%$ of AC yield and $99.75 \%$ for MG removal.

-Furthermore, for all the responses the error obtained from optimization results is less than $5 \%$, which prove a good agreement between the predicted values given by the RSM model and the experimental results.

In this study, the starting material used is very cheap and easy to get. The waste biomass is used as a precursor in order to prepare activated carbon by chemical activation with a good yield and high efficiency in order to remove cationic dyes.

\section{Acknowledgements}

This work financially supported by an Excellence Grant accorded to MOUGHAOUI FATIHA (016UH2M2014) by the National Center of Scientific and Technical Research (CNRST) Ministry of Higher Education, Scientific Research and Training, Morocco

\section{References}

1- T. H. Liou, Development of Mesoporous Structure and High Adsorption Capacity of Biomass-Based Activated Carbon by Phosphoric Acid and Zinc Chloride Activation, Chemical Engineering Journal, 2010, 158, 129-142.

2- D. Kalderis, S. Bethanis, P. Paraskeva, E. Diamadopoulos, Production of Activated Carbon from Bagasse and Rice Husk by a Single-Stage Chemical Activation Method at Low Retention Times, Bioresource Technology, 2008, 99, 6809-6816.

3- J. B. Castro, P. R. Bonelli, E. G. Cerrella, A. L. Cukierman, Phosphoric Acid Activation of Agricultural Residues and Bagasse from Sugar Cane: Influence of the Experimental Conditions on Adsorption Characteristics of Activated Carbons, Industrial \& Engineering Chemistry Research, 2000, 39, 4166-4172.

4- D. Angın, E. Altintig, T. E. Köse, Influence of Process Parameters on the Surface and Chemical Properties of Activated Carbon Obtained from Biochar by Chemical Activation, Bioresource Technology, 2013, $148,542-549$.

5- A. Fernando, S. Monteiro, F. Pinto, B. Mendes, Production of Biosorbents from Waste Olive Cake and Its Adsorption Characteristics for $\mathrm{Zn}^{2+}$ Ion, Sustainability, 2009, 1, 277-297. 
6- N.S. Sulaiman, R. Hashim, M. H. M. Amini, M. Danish, O. Sulaiman. Optimization of Activated Carbon Preparation from Cassava Stem Using Response Surface Methodology on Surface Area and Yield. Journal of Cleaner Production, 2018, 198, 1422-1430.

7- K. Mohanty, D. Das, M. N. Biswas, Adsorption of Phenol from Aqueous Solutions Using Activated Carbons Prepared from Tectona Grandis Sawdust by $\mathrm{ZnCl}_{2}$ Activation, Chemical Engineering Journal, 2005, 115, 121-131.

8- G. Crini, Non-Conventional Low-Cost Adsorbents for Dye Removal: A Review, Bioresource Technology, 2006, 97, 1061-1085.

9- Y. Zhu, H. Zhang, H. Zeng, M. Liang, R. Lu, Adsorption of Chromium (VI) from Aqueous Solution by the Iron (III)-Impregnated Sorbent Prepared from Sugarcane Bagasse, International Journal of Environmental Science and Technology, 2012, 9, 463-472.

10- M. Eddebbagh, A. Abourriche, M. Berrada, M. B. Zina, A. Bennamara, Adsorbent Material from Pomegranate (Punica Granatum) Leaves: Optimization on Removal of Methylene Blue Using Response Surface Methodology, J. Mater Environ Sci, 2016, 7, 2021-2033.

11- B. H. Hameed, A. L. Ahmad, K. N. A.Latiff, Adsorption of Basic Dye (Methylene Blue) onto Activated Carbon Prepared from Rattan Sawdust, Dyes and Pigments, 2007, 75, 143-149.

12- F. Moughaoui, M. Berrada, A. Bennamara, A. Abourriche, Z. Anbaoui, Adsorption study of methylene blue dye using Moroccan sugarcane bagasse, In Proceedings Rencontres Scientifiques sur l'Environnement - Morocco, 2016, 1, 109-115.

13- F. Moughaoui, A. Ouaket, M. Eddebbagh, A. Bennamara, A. Abourriche, Z. Anbaoui, M. Berrada, Study of Adsorption Isotherms and Kinetic Models of Methylene Blue Adsorption on Moroccan Bagasse Waste, $7^{\text {th }}$ International Conference on Innovation in Chemical, Agricultural, Biological and Environmental Sciences (ICABES-2017); HEAIG: UK, 2017, 59-65.

14- A. M. M. Vargas, A. L. Cazetta, M. H. Kunita, T. L. Silva, V. C. Almeida, Adsorption of
Methylene Blue on Activated Carbon Produced from Flamboyant Pods (Delonix Regia): Study of Adsorption Isotherms and Kinetic Models, Chemical Engineering Journal, 2011, 168, 722-730.

15- V. K. Gupta, Suhas, Application of Low-Cost Adsorbents for Dye Removal - A Review, Journal of Environmental Management, 2009, 90, 2313-2342.

16- H. Ali, Biodegradation of Synthetic Dyes - A Review, Water, Air \& Soil Pollution, 2010, 213, 251-273.

17- S. S. Salih, T. K. Ghosh. Highly Efficient Competitive Removal of $\mathrm{Pb}(\mathrm{II})$ and $\mathrm{Ni}$ (II) by Chitosan/Diatomaceous Earth Composite. Journal of Environmental Chemical Engineering, 2018, 6, 435-443.

18- S. S. Salih, T. K. Ghosh. Preparation and Characterization of Chitosan-Coated Diatomaceous Earth for Hexavalent Chromium Removal. Environmental Processes, 2018, 5, 23-39.

19- J. N. Sahu, J. Acharya, B. C. Meikap, Optimization of Production Conditions for Activated Carbons from Tamarind Wood by Zinc Chloride Using Response Surface Methodology, Bioresource Technology, 2010, 101, 1974-1982.

20- M. Danish, T. Ahmad, W. N. A. W. Nadhari, M. Ahmad, W. A. Khanday, L. Ziyang, Z.O. Pin. Optimization of Banana Trunk-Activated Carbon Production for Methylene BlueContaminated Water Treatment. Applied Water Science, 2018, 8, 9 .

21- J. Goupy, L. Creighton, Introduction aux plans d'expériences, ed. 3, by Dunod: Paris, 2006, pp. 320.

22- D. As, K. Mh, M. Lr, Optimization of the Process Parameters for the Preparation of Activated Carbon from Low-Cost Phoenix Dactylifera Using Response Surface Methodology, Austin Chem Eng, 2015, 2, 9.

23- Y. S. Mohammad, E. M. Shaibu-Imodagbe, S. B. Igboro, A. Giwa, and C. A. Okuofu, Modeling and Optimization for Production of Rice Husk Activated Carbon and Adsorption of Phenol, Journal of Engineering, 2014, 2014, $1-10$. 